\title{
EDITORIALS
}

\section{Island Dilemmas}

As we delve deeper and deeper into the intricate processes of ecological systems, so it becomes obvious that the simplistic boundaries which we erected to facilitate the progress of our science are all-too-often out of keeping with the real world that we are striving to understand. The discovery of continua in Nature is widely overriding our artificial classifications, which stood only as long as our information was lacking in detail; now, in attempting to predict natural events, we can usually speak in terms only of probabilities, not of certainties.

This predicament is exemplified by what has latterly come to be termed 'the island dilemma': in summary, the Earth's natural areas are tending more and more towards a state of insularity. As they are encroached upon and intentionally set aside as nature reserves, which become islands of wild Nature in 'seas' of man-altered habitat, so we can expect them -on island biogeographical grounds-to show increasingly diminishing returns as far as the natural diversity that they contain is concerned. The fallacy in which we have believed is that Nature can be preserved in small isolated pockets, scattered here and there across the surface of the Earth.

The crux of the dilemma seems to be a vicious circle: wild Nature can only be preserved if we can come to reconcile its conservation with human development-in other words, prove that nature conservation is in our best long-term interests. Yet diverse Nature will only survive if left to itself, without being subjected to the values that human development imposes. It seems that Man and wild Nature - as we know it still in a few relict areas in the biosphere-can only coexist in unstable equilibrium. To most people, however, watered-down Nature is at least as good as its diverse predecessor: in spite of their popularity, even wild populations of lions, tigers, and elephants, for example, are being rapidly depleted, so what of all the unpopular creatures such as sharks, snakes, and poisonous plants, and of the myriads of lesser-known ones? To people who still live in wild places, Nature is rarely more than an opponent to survival, while to those of the industrial world, Nature is to be admired occasionally, at most, and even then only with the assistance of technology. Conservationists have even been accused on occasion of putting 'wildlife before Man'; so how important are wildlife, wilderness, and natural diversity?

We know inter alia that some degree of natural diversity is essential to Man (for example as a genetic resource); that wild areas are to some extent a psychological resource allowing the spiritual fulfilment that is so inextricably a part of our cultures and minds, and that living Nature is part of the processes which somehow determine the climate and other biospheral processes on which our lives depend: in short, many of us recognize that Nature knows much that we do not. Science, however, regards this uncertainty as merely a passing problem; yet one need only look at the human communities of oceanic islands today to see how far life has been impoverished by lack of foresight in natural resource use. According to many, even the island dilemma which human expansion faces in the finiteness of the biosphere is a predicament that can be solved with more information of the appropriate kinds.

It is becoming increasingly clear, however, that the time-scale required for Man to transgress the natural boundaries of the biosphere is far greater than that for the appearance of critical problems for human development. It is obvious that science must come to terms with itself, and be able to assimilate and continually respond to its own edicts. We know now that full natural diversity cannot survive in an insular form; yet clearly Man must recognize his limitations, for the 'ocean' that lies beyond the reaches of contemporary knowledge will not favour him for ever.

$$
\text { N.V.C.P. }
$$

\section{The Beirut Syndrome}

Is one of the above island dilemmas the senseless, even wanton, human killing that seems to be spreading widely nowadays and in some unhappy places amounts to chronic if small-scale massacre? And could not this deplorable tendency all-too-easily and rapidly grow to major proportions, involving tens of thousands and in time many millions of peoplefor instance, with the real shortages of food and space that seem widely inevitable if island and other territorially restricted populations continue to expand as at present?

The occasion of our awakening in this matter was one not unknown to early readers of this Journal (Vol. 1, p. 92), when we were discussing how the world's basic dilemma of human population-swarming might conceivably be settled. We were holding forth on the relative 'merits' of widespread famine, nuclear holocaust, some uncontrollable pandemic sweeping an unprepared and disrupted world, and insidious disappearance of the vegetational life-support system, when one of our number, a wise and eminent man, contended that none of these would be necessary - that in due course human beings would come to killing one another in sufficient numbers to solve the world's population problem.

Asked if he really meant this, he affirmed that he was advancing the hypothesis in all seriousness, as he was unhappily convinced that this would be the course of events; for we all felt that the chances of Man's peaceful and voluntary control of his own numbers by the means now at his disposal were slim. This got us thinking of various places and situations in different parts of the world where small-scale killing was already proceeding and large-scale extensions seemed all-tooconceivable without any declaration of war, but using horrifying methods and weaponry. We had then the Near East and Cyprus, southeastern Asia, Northern Ireland, and various parts of Africa and Latin America: all of these and some others continue as hot-spots today. But there are now added grave intensifications in Africa, Northern Ireland, the Far East, and especially Lebanon, where, in the fine old capital of Beirut, the latest killings, amounting already to thousands *, are matched in vicious intensity only by their wanton nature; hence our above sad title, and our abiding dejection as we go to press in this New Year.

N.P.

* According to the International Herald Tribune of 9 January 1975 (p. 1), on the preceding day the 'estimated toll for nine months of civil war rose to nearly 8,150 dead and 16,400 wounded', while three days later they reported that these numbers had risen 'to more than 8,400 dead and 17,860 wounded'. These last followed police reports, but a private one which came to us from a recent resident added 'many thousands missing'. 